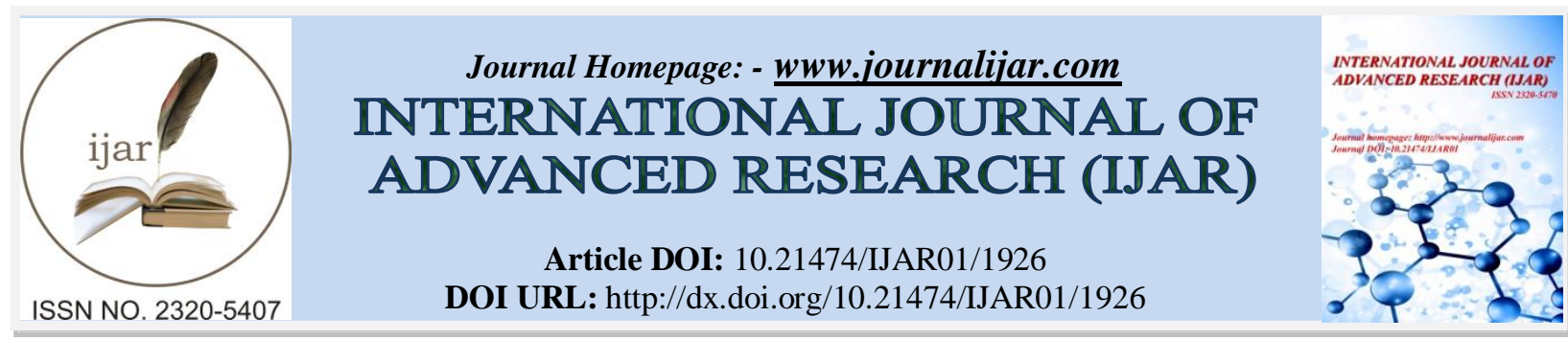

RESEARCH ARTICLE

\title{
ROLE OF SMART MEDIUM SUPPLEMENTED WITH FOLLICULAR FLUID IN IN VITRO MATURATION FOR SHEEP IMMATURE OOCYTES RECOVERED FROM XENOTRANSPLANTED OVARIAN TISSUE CORTEX.
}

\author{
Prof. Dr.Muhammad Baqir M.R. Fakhrildin, Dr. Nadia J.Sudani Al-Behadili and Prof. Dr.Mohammad Oda \\ Selman.
}

Mohammad Oda Selman (FIBMS). Head of clinical Applied Embryology Department in High Institute of Infertility diagnosis and ART.

\section{Manuscript Info}

Manuscript History

Received: 10 August 2016

Final Accepted: 26 September 2016

Published: October 2016

Key words:-

Ovarian tissue transplantation, in vitro maturation and xenotransplantion.

\section{Abstract}

Background:- Ovarian tissue transplantation (OTT) is becoming an increasingly popular strategy for fertility preservation, the original indication was to restore fertility to young women who undergo chemotherapy or radiotherapy for cancer, and theyface serious consequences to their reproductive health and severely affect the ovarian follicular store.However, there is an increasing public awareness of its availability as a potential fertility preservation strategy for those at risk.

Objective:- To assess in vitro maturation (IVM) for sheep oocytes recovered from immature follicles using SMART medium enriched with follicular fluid (FF) using xenotransplanted ovarian tissue cortex inside body of female mice injected with or without different hormonal stimulation protocols.

Material and Methods:- Seventy five healthy and maturefemale mice were anesthesized and a small slit was made in the abdomen and peritoneum from one side of the body, follicular fluid (FF) was aspiratedfrom sheep ovarian follicles and small piece $(2 * 2 \mathrm{~mm}$ in area and $1 \mathrm{~mm}$ in thickness) of the sheep ovariantissue(OT) were transplanted to the inner side of the peritonium with the abdominal wall, then femalemice were classified into two groups. Group A: control.Group B:underhormonal programs.For stimulation follicular development intraperitoneally injection with PMSG 15 IU daily for 3 days, and PMSG 10 IU with HCG 10 IU in the fourth day, in the fifth day HCG 10 IU was given only.After 6days, the sheep ovarian cortex was recovered from mice then oocytes were collected by slicing for in vitro maturation (IVM) and classified into three groups. Group1: oocytes with SMART medium alone (control group).Group2: oocytes with SMART medium enriched with 5\% F.F. and lastly Group3: oocytes with SMART medium supplied with $10 \%$ F.F. Follicular growth, quality ofretrieved ova and histological changes fortransplanted OT were assessed.

Results:- The results of this study demonstrated significant $(P<0.05)$ differences in the number of oocytes between group G2 as compared to groupG1, as control group, $(p=0.024)$ in group A, Furthermore, 
group G3 revealed highly significant differences $(p<0.001)$ were assessed among each two groups of the present study.

In group B, the numbers of retrieved ova have significant differences for the group G2 and group G1, as control group, in the present study where $(p=0.036),(p=0.048)$ respectively, when compared to groups G3 with group G1. A high significant between group G2 comparing $\mathrm{G} 3(P<0.001)$ was noticed.

Conclusions:- From results of the present study it was concluded that an in vitro maturation for sheep oocytes is possible from xenotransplanted ovarian cortex tissue within mouse peritonium. Further histobiochemical studies are recommended to investigate role of apoptosis in the production of sheep oocytes recovered from xenotransplanted ovarian cortex.

Copy Right, IJAR, 2016,. All rights reserved.

\section{Introduction:-}

The number of primordial follicles in the ovarian tissue is an important determinant for the length of the ovarian lifespan, and therefore the fertility of an individual. This tissue contains all of the oocytes potentially available for fertilization throughout the fertile lifespan of female ${ }^{(1)}$.

The ovarian cortex has thousands of primordial follicles, which can survival viable even several hours after ovariectomy $^{(2)}$. These follicles were recovered successfully for future xenotransplantation, ${ }^{(3)}$ or in vitro culture to obtain mature oocytes potentially fertile. Thus, the whole ovary, isolated cortical tissue and ovarian follicles may be used to protect gametes of the female ${ }^{(4)}$ who suffering from malignant diseasesand have no option of utilizing assisted reproductive technologies (ART) to preserve their fertility ${ }^{(5)}$.

When the recipient and the donor are from the same species, but not genetically identical, the transplant is called allotransplantation, while transplantation between different species is called xenotransplantation ${ }^{(6)}$. In both cases, the graft is subject to the risk of rejection by the recipient's immune system. Many attempts have been made to avoid rejection in allo- and xenograft mammalian animal models, human organ and tissue transplantation ${ }^{(7)}$.

The full potential of this tissue to restore fertility could be achieved by the development of in vitro systems that support oocyte development from the most immature stages to maturation. The techniques of in vitro maturation (IVM) are being developed in human ${ }^{(8)}$.Generally IVM refers to the maturation of immature oocytes in culture after their recovery from small antral follicles at the stage prior to selection and dominance. It has been proposed as an alternative to conventional in vitro fertilization (IVF), since it reduces the primary adverse effects caused bycontrolled ovarian stimulation ${ }^{(9)}$. Moreover, there is no universal or consensus protocol for optimal timing of oocyte collection in IVM cycles. However, the pregnancy rate following IVM is suboptimal compared with that of conventional IVF.Therefore, more studies are needed in order to identify factors that predispose these IVM cycles to success or failure ${ }^{(10)}$. Therefore the aim of this study was to demonstrate role of SMART medium in invitro maturation (IVM) for sheep immature oocytesfrom ovarian tissue transplanted in the presence or absence of stimulation hormones.

\section{Material and Methods:-}

Animals(sheep and mice:-

This study was performed using sheep ovaries of randomly ewes which were slaughtered in AL-Shualla local abattoir and carried out within 1 hour to the laboratory of the High Institute for Infertility Diagnosis and Assisted Reproductive Technologies, AL-Nahrain University, during the period from September 2015 to April 2016. Sheep ovaries were chosen as model due to their anatomic and physiological similarities of their ovaries comparing to those of human, moreover folliculogenesis is also relatively similar in both species ${ }^{(11)}$.

The female mice were given from Animal House unit in High Institute for Infertility Diagnosis and Assisted Reproductive Technologies. Isolated female mice should be as healthy, mature and not pregnant. The mice were 
chosen because the mouse is an ideal model organism for human study, not only mice physiologically is similar to humans, but also it has specific characteristics that resemble to human ${ }^{(12)}$.

\section{Collection of sheep ovaries:-}

The sheep ovaries were collected from local abattoir (AL-Shullah) at Baghdad.

Both ovaries were collected from each animal immediately after slaughtering and placed into glass container contained normal salinesolution $(0.85 \% \mathrm{NaCl})$ supplemented with antibiotics $(100 \mathrm{IU} / \mathrm{ml}$ penicillin, $100 \mu \mathrm{g} / \mathrm{ml}$ streptomycin and $100 \mu \mathrm{g} / \mathrm{ml}$ metronidazole), and placed it into thermos at $30-35^{\circ} \mathrm{C}$. Ovaries were transported to the laboratory at of High Institute for Infertility Diagnosis andAssisted Reproductive Technologies, within less than 1 hour. In the laboratory, ovaries were washed three times with warmed $\left(30^{\circ} \mathrm{C}\right)$ normal saline solution $(0.85 \% \mathrm{NaCl})$ supplemented with antibiotics (100IU/ml penicillin and $100 \mu \mathrm{g} / \mathrm{ml}$ streptomycin). This process to remove the blood clotting and the reducing contamination on the ovarian surfaces ${ }^{(13)}$.

Aspiration and Preparation of follicular fluid:-

Aspirated of follicular fluid (FF) from the visible ovarian antral follicles on the ovarian surface using disposable syringe containing SMART medium $0.5 \mathrm{ml}$ and heparin 0.01 , and then transferred to the test tube to centrifuge at $2600 \mathrm{rpm} / 8 \mathrm{~min}$. at $15^{\circ} \mathrm{C}$. Aspirated upper layer of $\mathrm{FF}$ and put it in water bath at $56^{\circ} \mathrm{C}$ for $30 \mathrm{~min}$.then freezing it at $20^{\circ} \mathrm{C}$ until use.

\section{Preparation of ovarian cortex fragments:-}

Each ovary was split into two halves, and then cortex and medulla were separated with a scalpel blade. The cortex of each ovary was further sectioned into small fragment $(2 * 2 \mathrm{~mm} \text { in area and } 1 \mathrm{~mm} \text { in thickness })^{(14)}$.Then transferred intoPetri dish containing $0.5 \mathrm{~mL}$ of SMART mediumto xenotransplantation and other fragments transferred to test tube containing $10 \%$ formaldehyde to histological preparation ${ }^{(15)}$.

\section{Xenotransplantation of ovarian cortex:-}

For the xenotransplantation, female mice were anesthetized using inhaled Ether and a small slit was made in the abdomen and peritoneum from one side of the body, the sheep ovarian cortex fragments were transplanted to the inner side of the peritoneum with the abdominal wall and closed by 1 or 2 stiches ${ }^{(16)}$.

For immunological inhibition, every mouse was administered orally Prisolone (Prednisolone) $(0.178 \mu \mathrm{g})$ daily. For stimulation follicular development intraperitoneally injection with 15 IU PMSG daily for 3 days, and 10 IU PMSG with 10 IU HCG in the fourth day, in the fifth day 10 IU HCG was given only.After 6 day, the sheep ovarian cortex was taken out from mice and washed three times in SMART medium, then oocytes were collected by slicing ovarian cortex fragment, another sheep ovarian cortex was taken out from mice to histological examination.

\section{Ovulation Induction Programs (OIP):-}

- Group A: control (female mice without any medication).

- GroupB: hormonal programs (female mice under hormonal stimulation protocols).

Day1: FSH 15 IU.Day2: FSH 15 IU. Day3: FSH 15 IU.Day4: FSH 10 IU + HCG 10 IU. Day5: HCG 10 IU.

For IVM group, oocytes classified into three groups:

Group 1: oocytes with SMART medium alone (control group).

Group 2: oocytes with SMART medium enriched with 5\% F.F

Group 3: oocytes with SMART medium enriched with $10 \%$ F.F

\section{Assessment of ova morphology after IVM:-}

Oocytes were washed three times in SMART medium containing 20\% HSA, then, about 5-10 oocytes per droplet

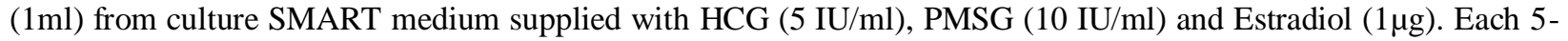
10 oocytes per droplet $(1 \mathrm{ml})$ was supplied with $5 \%$ F.F and another with $10 \%$ F.F, then cultured within four well Petri dish and covered their by liquid paraffin and incubated for about $24 \mathrm{hr}$ in $\mathrm{CO}_{2}$ incubator $\left(5 \% \mathrm{CO}_{2}\right)$ at $38.5^{\circ} \mathrm{C}$ with high humidity $(95 \%)^{(17)}$. Then examine under an inverted-phase microscope to assessment of ova morphology. The percentage of IVM was recorded by based onthe following equation: IVM\% = mature oocytes / cultured oocytes $* 100$ 


\section{Histological preparation:-}

The preparation of histological sections of ovarian tissue depends on the standards methods of Allen and Cameron $(2004)^{(18)}$.The histological parameters were carried out using Images J. software.

\section{Statistical analysis:-}

The data were statistically analyzed using statistical computerized package (SPSSversion-21) by application the number and percentage of Chi-square analysis test, a $p$ value of $<0.05$ was considered statistically significant.Histological parameters were analyzed using complete randomized design (CRD) (one way ANOVA) ${ }^{(19)}$.

\section{Results:-}

Effect of xenotransplantation techniques on number of retrieved oocytes of control group:-

The results of this study demonstrated significant $(P<0.05)$ differences in the number of oocytes between group G2 as compared to group G1, as control group, $(p=0.024)$ (Table1). From the same table, group G3 revealed highly significant differences $(p<0.001)$ were assessed among each two groups (G1 and G2) of the present study. The highly percentage of mature oocytes were in group G2 (culture media enriched with 5\% FF), with lower percentage of atretic oocytes in same group.

Table 1:- Effect of xenotransplantation on the percentage of retrieved oocytes of control group.

\begin{tabular}{|c|c|c|c|c|c|c|c|c|}
\hline \multirow{2}{*}{$\begin{array}{l}\text { Xenotransplantation } \\
\text { G AControl group }\end{array}$} & \multicolumn{8}{|c|}{ Oocyte Recovery } \\
\hline & \multicolumn{2}{|c|}{ Immature } & \multicolumn{2}{|c|}{ Mature } & \multicolumn{2}{|c|}{ Atretic } & Total & $p$-value \\
\hline G1CM group & 13 & 34.2 & 9 & 23.7 & 16 & 42.1 & 38 & - \\
\hline $\begin{array}{c}\mathrm{G2} \\
\text { CM enriched with } 5 \% \mathrm{FF}\end{array}$ & 7 & 17.9 & 19 & 48.7 & 13 & 33.3 & 39 & $0.024 *$ \\
\hline $\begin{array}{c}\text { G3 } \\
\text { CM enrichedwith } 10 \% \text { FF }\end{array}$ & 16 & 39.1 & 6 & 14.6 & 19 & 46.3 & 41 & $\begin{array}{l}<0.001 * * \\
<0.001 * *\end{array}$ \\
\hline
\end{tabular}

${ }^{\#}$ Chi -square test at 0.05 the level of significance; ${ }^{\#} \mathrm{CM}$ culture media

*G1\&G2: $P=0.024$ Significant; **G1\&G3 P<0.001 highly significant; **G2\&G3 P<0.001 Highly significant

Effect of xenotransplantation techniques on number of retrieved oocytes of hormonal stimulated group:-

The results of ova retrieval and classification related to hormonal stimulated groups were presented in the table (2). The numbers of retrieved ova havesignificant differencesfor the group G2 and group G1, as control group, in the present study where $(p=0.036),(p=0.048)$ respectively, when compared to groups G3 with group G1. Ahigh significant between group G2 comparing G3 $(P<0.001)$ was noticed.The highly percentage of mature oocytes were in group $\mathrm{G} 2$ (culture media supplied with $5 \% \mathrm{FF}$ ).

Table 2:- Effect of xenotransplantation on the percentage of retrieved oocytes of hormonal stimulated group.

\begin{tabular}{|c|c|c|c|c|c|c|c|c|}
\hline \multirow{2}{*}{$\begin{array}{c}\text { Xenotransplantation } \\
\text { G B } \\
\text { Hormonal stimulated group }\end{array}$} & \multicolumn{8}{|c|}{ Oocyte Recovers } \\
\hline & \multicolumn{2}{|c|}{ Immature } & \multicolumn{2}{|c|}{ Mature } & \multicolumn{2}{|c|}{ Atretic } & Total & $P$-value \\
\hline $\begin{array}{c}\text { G1 } \\
\text { CM group }\end{array}$ & 8 & 19.1 & 20 & 47.6 & 14 & 33.3 & 42 & - \\
\hline $\begin{array}{c}\text { G2 } \\
\text { CM enriched with 5\% FF }\end{array}$ & 10 & 22.2 & 28 & 62.2 & 7 & 15.6 & 45 & $0.036^{*}$ \\
\hline $\begin{array}{c}\text { G3 } \\
\text { CM enrichedwith } 10 \% \text { FF }\end{array}$ & 14 & 30.4 & 17 & 32.6 & 15 & 36.6 & 46 & $\frac{0.048^{*}}{<0.001 * *}$ \\
\hline
\end{tabular}

*G1\&G2: $P=0.036$ Significant; $*$ G1\& G3: $P=0.048$ Significant; **G2\&G3 $P<0.001$ Highly significant

\section{Discussion:-}

The human ovarian grafts contained large numbers of germ cells about 11,000 primordial follicles, an amount that could provide oocytes for a year ${ }^{(20)}$. This study aimed to improve a successful follicular development after ovarian tissue transplantation (OTT) intraperitoneally in mice. Ovarian transplantation appears to be simple and novel technique to preserve endocrine function in women who undergoing sterilizing cancer therapy or surgery ${ }^{(21)}$. 
Results of the present work appeared that the number of antral follicles is too little, in G3 which may be as a result of environmental and side effects on transplanted ovarian tissue (OT). The optimal number of retrieved oocytes depends on the ovarian stimulation regimen ${ }^{(22)}$. However, age and season both significantly affect the response of oocyte developmental competence to FSH stimulation ${ }^{(23)}$. A number of parameters were also significantly affected by donor age. In fact the total number of follicles decreased with age ${ }^{(24)}$.

Significant $(P<0.05)$ differences in the number of atretic ova was assessed among three groups of this study. This result may be partially due to technical method for ovarian tissue recovery and/or retrieval of oocytes ${ }^{(20)}$, so as the transplant site might itself influence follicle recruitment and atresia. The reduction in the number of ovarian follicles may be as a result of follicular atresia due to ischemia and apoptosis of primordial and primary follicles ${ }^{(25)}$. The ischemic insult of the ovarian tissues is associated with comparable alterations in special molecules is still unknown (26). Warm ischemia time was very long (more than $3 \mathrm{~h}$ ) and it is well known clinical transplant surgery that these long warm periods induced ischemic significant damage to organs and blood vessels ${ }^{(27)}$. It was known that atretic follicles may reflect the pre-existing atretic changes instead of the effect of (OTT) ${ }^{(28)}$. Also, it was certified that an important technical limitation of cortical grafting, whether orthotopic or heterotopic, is the potential for follicle atresia during the period of ischemia ${ }^{(29)}$. Furthermore, presence of atretic and/or abnormal oocytes, in the present study, may be reflecting wide range of fluctuation of gonadotropins and/or inadequate exposure to gonadotropins which led to abnormal follicular development and subsequently produce abnormal and atretic oocytes. This result is in agreement with results of several investigators ${ }^{(30)}$.

Follicular fluid (FF) provides a very important microenvironment for the development of oocytes. It is reasonable to think that some biochemical characteristics of the FF surrounding the oocyte may play a critical role in determining oocyte quality and the subsequent potential to achieve fertilization and embryo development ${ }^{(31)}$.

Results of current work improved that the levels of hCG hormone, FSH and LH are well recognized as the physiologic stimulants of oocyte maturation during the final stages of pre-ovulatory development. Numerous studies in a variety of mammalian species suggest that there are certain hormonal requirements during the in vitro maturation (IVM) of mammalian oocytes, which are significant for fertilization and developmental competence ${ }^{(32)}$.

Therefore, from results of the present study it was concluded that an in vitro maturation for sheep oocytes is possible from xenotransplanted ovarian cortex tissue within mouse peritonium. Further histobiochemical studies are recommended to investigate role of apoptosis in the production of sheep oocytes recovered from xenotransplanted ovarian cortex.

\section{References:-}

1. Findlay JK, Hutt KJ, Hickey M,et al.How Is the Number of Primordial Follicles in the Ovarian Reserve Established? Biol Reprod. 2015; 93(5):111.

2. Silva $\mathrm{JR}^{1}$, Lucci CM, CarvalhoFC,et al. Effect of coconut water and Braun-Collins solutions at different temperatures and incubation times on the morphology of goat preantral follicles preserved in vitro. Theriogenology. $2000 ; 15 ; 54(5): 809-22$.

3. Paris MC, Snow M, Cox SL, et al. Xenotransplantation: a tool for reproductive biology and animal conservation? Theriogenology. 2004; 15; 61(2-3):277-91.

4. Batuhan O1, Safaa AH. Techniques for ovarian tissue, whole ovary, oocyte and embryo cryopreservation. J ReprodInfertil. 2010; 11(1):3-15.

5. Andersen CY, Rosendahl M, Byskov AG, et al. Two successful pregnancies following autotransplantation of frozen/thawed ovarian tissue.HumReprod. 2008; 23(10):2266-72.

6. Lakkis FG. The immune response to a transplanted organ: an overview. Page 3-9 in immune therapy in transplantation. Cryobiology Journal. 2012; 60, P: 101-05.

7. Tisato V, CozziE. Xenotransplantation: an overview of the field. Methods Mol Biol. 2012; 885:1-16.

8. Telfer EE1, ZelinskiMB. Ovarian follicle culture: advances and challenges for human and nonhuman primates. FertilSteril. 2013; 99(6):1523-33.

9. Chang EM, Song HS, Lee DR, et al. In vitro maturation of human oocytes: Its role in infertility treatment and new possibilities. ClinExpReprod Med. 2014; 41(2):41-6.

10. Son WY, ChungJT, HerreroBet al. Selection of the optimal day for oocyte retrieval based on the diameter of the dominant follicle in hCG primed in vitro maturation cycles. Human Reproduction Journal.2008; 23(12): 2680-85. 
11. MerdassiG, MazoyerC, Guerin JF, et al. Examination of viability and quality of ovarian tissue after cryopreservation using simple laboratory methods in ewe.ReprodBiolEndocrinol. 2011;9(78).

12. Mary A, Nancy A, and Neal G. Mouse models of human disease. Part I: Techniques and resources for genetic analysis in mice.Genes Dev. 1997; 11(1):1-10.

13. Rezk W.A.K. Studies on in vitro fertilization in camels (camelus dromedaries). PhD thesis. Faculty of Agriculture, Animal Production Department, Mansoura University, 2009.

14. FransoletM, LabiedS, HenryL , et al. Strategies for Using the Sheep Ovarian Cortex as a Model in Reproductive Medicine. Journal pone.2014; 10; 9(3).

15. Fakhrildin MB, and Flayyih NK. Anew simple medium for in vitro sperm activation of asthenozoospermia patient using direct swim-up technique. KufaMed.Journal. 2011; 14 (1).

16. Marie-madeleine D. Cristina M. Pascale S, et al. Reimplantation of cryopreserved ovarian tissue from patients with acute lymphoblastic leukemia is potentially unsafe. Blood Journal.2010; 116(16): 2908-2914.

17. De Felici M. and Siracusa G. Spontaneous. Hardening of the zonapellucida of mouse oocytes during in vitro culture. Gamete Research Journal. 1982; 6(2): 107-113.

18. Allen D.C. and Cameron I.R. Histopathology Specimens;Clinical, pathological and Laboratory Aspects. $1^{\text {st }}$ edition. UK. Springer Puplishing. 2004:225-235.

19. Duncan DB. Multiple range and multiple F test. Biometrics Journal.1955; 11, P: 1-42.

20. Smitz J. Oocyte developmental competence after heterotopic transplantation of cryopreserved ovarian tissue. The Lancet, Comment. 2004; 1-2.

21. Oktay K, Economos K, Kan M, et al. Endocrine function and oocyte retrieval after autologous transplantation of ovarian cortical strips to the forearm. JAMA. 2001; 286:1490-93.

22. Verberg MF, Eijkemans MJ, Macklon NS, et al .The clinical significance of the retrieval of a low number of oocytes following mild ovarian stimulation for IVF: a meta-analysis.Hum Reprod Update. 2009; 15(1):5-12.

23. Sandra B, Angela G, ValbuenaD, et al. Effect of age and coasting period on oocytes quality and their in vitro development from prepubertal cattle. Rev.MVZ Córdoba.2011; 16(2):2499-2506.

24. Wolf. E. Effect of donor age on the developmental capacity of bovine cumulus oocyte complexes obtained by repeated OPU from non stimulated and FSH-super stimulated German Simmental heifers and cows at different life cycle stages. 2011.

25. Kim SS. Ovarian tissue banking for cancer patients: To do or not to do. Hum. Reprod. 2003; 18: 1759-61.

26. Hussein MR, Bedaiwy MA, Falcone T. Analysis of apoptotic cell death, Bcl-2 and p53 protein expression in freshly fixed and cryopreserved ovarian tissue after exposure to warm ischemia. FertilSteril. 2006; 85:1-12.

27. Jeremias E, Bedaiwy MA, Gurunluoglu R, et al. Heterotopic autotransplantation of the ovary with microvascular anastomosis: a novel surgical technique. FertilSteril. 2002;77(6): 1278-82 .

28. Bedaiwy MA, Jeremias E, Gurunluoglu R, et al .Restoration of ovarian function after autotransplantation of intact frozen-thawed sheep ovaries with microvascular anastomosis. FertSteril. 2003; 79: 594-602.

29. Silber SJ, Lenahan KM, Levine DJ, et al. Ovarian transplantation between monozygotic twins discordant for premature ovarian failure. N Engl J Med. 2005; 353: 1-6.

30. Callejo J, Salvador C, Miralles A, et al. Long-term ovarian function evaluation after autografting by implantation with fresh and frozen-thawed human ovarian tissue. J ClinEndocrinolMetab. 2001; 86:4489-94.

31. Revelli A, DellePiane L, Casano S,et al.Follicular fluid content and oocyte quality: from single biochemical markers to metabolomics. Reprod Bio Endo.2009; 40(7).

32. Armstrong DT,Zhang X, Vanderhyden BC, et al. Hormonal actions during oocyte maturation influence fertilization and early embryonic development. Ann N Y Acad Sci. 1991; 626:137-58. 